\title{
Seduz-me. Deseja-me. Ou talvez não - A voz dramática do desejo
}

\author{
CÁTIA FAÍSCO
}

Since ancient times, sexual desire has been the object of multiple philosophical reflections and has served as a magnetic compelling force for the creation of the most diverse artistic oeuvres. In the theatrical context, its potential has been explored and (re)presented not only through a dramaturgical tradition, but also through its performative materialization. Therefore, this article proposes a brief approach to the subject of sexual desire, its significance and meanings within contemporary British drama, having has an example the voice of the post-in-yerface generation of playwrights such as Nick Payne, Anya Reiss Penelope Skinner, among others. The chosen authors disclose a portrait of the 2000's society (20002015), and their plays were transformed into shows that premiered at the Royal Court Theater in London. This article also aims to understand how sexual desire is communicated within a dialogue and how its characters convey (or not) a naturalistic approach of the playwrights' perspective on their contemporary society.

SEXUAL DESIRE / ROYAL COURT THEATRE / UK / CONTEMPORARY THEATRE

I had all this, this... urgh; inside me, I couldn't sit still, I couldn't concentrate, there weren't enough wanking hours in the day. The only thing that made it better was the little library Dad had packed me. I devoured every book, cover to cover. She became my aged Lady Chatterley, my jaded Juliet, my latter-day Anna Karenina, but I was Quasimodo-looking longingly from afar, catching glimpses of her perfection whilst I remained this skinny, pasty and increasingly terrified teenager. It killed me; the more time I spent with her, the worse it was.

Jude, in Eight, Ella Hickson

Em 2013, Ella Hickson escreveu Eight, uma ideia estrutural para um espetáculo composto por oito monólogos, onde o público escolhia diariamente apenas quatro para assistir em palco. A cada um dos textos,

FAÍSCO, CÁTIA (2020), «SEDUZ-ME. DESEJA-ME. OU TALVEZ NÃO - A VOZ DRAMÁTICA DO DESEJO», SINAIS DE CENA II, N. ${ }^{\circ} 4$, 
a dramaturga atribuiu como título o nome da personagem que contava a história. $\mathrm{O}$ exemplo supracitado é proferido por Jude, jovem adolescente prestes a entrar na idade adulta que deseja secretamente a diretora do colégio francês para onde foi enviado durante as férias do verão. O pai, que ambiciona que o filho aprenda a língua, quer vê-lo transformado num homem. Contudo, é precisamente através da língua do amor e dos livros que o pai lhe enviou que Jude se entrega à ideia de conquistar a inalcançável mulher que, mesmo sem o saber, o remete para um frenesi de desejos sexuais que querem ser libertados.

Hickson é apenas um dos muitos exemplos dos jovens dramaturgos britânicos, entre os vinte e os quarenta anos, que começaram a sua carreira na viragem do milénio, depois do in-yer-face - movimento surgido nos anos 90 que revelou nomes tão importantes e determinantes da história da dramaturgia contemporânea britânica como Sarah Kane, Mark Ravenhill, Jez Butterworth, Martin Crimp, entre outros. Os dramaturgos do novo milénio que serão aqui tidos como exemplo têm, nesta sucinta análise sobre o desejo sexual, outra característica em comum: todos apresentaram uma obra no mítico Royal Court Theatre. Este teatro londrino ficou conhecido, precisamente nos anos 9o, como o epicentro da new writing, uma escrita com linguagem contemporânea e com uma abordagem mais experimental, e como o grande precursor de uma nova voz dramatúrgica. Embora, ao longo dos últimos anos, os seus diretores artísticos se tenham esforçado por manter o mesmo impacto junto do público e media, é notório que a premissa que distinguia o Royal Court Theatre se tornou atualmente na apologia de quase todos os teatros londrinos.

Considerando que a geração dos anos 90 transformou a urgência de se fazer ouvir numa linguagem mais visceral onde o sexo, o desejo e o amor eram temas incontornáveis, o poder da narrativa passou a veicular a necessidade de contar uma história. Numa zona oposta, a geração dos 2000 caracteriza-se precisamente pela ausência de uma história. Consequentemente, a representação do sexo, do desejo e do amor enfrenta uma estagnação que remete novamente para uma sociedade mais conservadora e mais fechada. No entanto, esta visão contrasta com a de Tony Blair, quando o então primeiro-ministro conjetura a reformulação do Reino Unido e a promoção das suas indústrias criativas e culturais, através do regresso da magnetizante Cool Britannia-que não era mais do que um modelo criado nos anos 90 para exportar tudo o que era cool na cultura britânica. Mas, na verdade, o que é mais poderoso e impactante do 
que o amor e o sexo? Nas palavras de Sierz (2011), o novo milénio trouxe um lugar onde o amor não só se estilhaçava, como também lançava todos os seus fragmentos ao vento; onde o casamento se tornava cada vez menos popular; o speed dating alcançou um lugar de destaque e onde, apesar do sexo sem compromissos, a maioria das pessoas procurava o amor. A diversificação das relações e do seu modo de expressão na esfera social não deixa, de certa forma, de remeter para a fragilidade temporária daquilo que o sociólogo Zygmunt Bauman (2003) apelidou de top-pocket relationships. A natureza deste tipo de relações caracteriza-se, entre outros parâmetros, por ser descartável, e por se poder tirar do bolso quando se precisa dela e voltar a arrumá-la quando já não faz sentido.

Para exemplificar esta ideia, recorre-se a The Village Bike, peça escrita em 2013 por Penelope Skinner. Nesta obra, a dramaturga não só demonstra que o amor não conquista tudo, como também apresenta caminhos alternativos para a consumação do desejo. Becky, a personagem central da peça, é uma esposa grávida que, perante todas as suas alterações hormonais, tenta que o marido aplaque a volúpia que lhe consome o corpo. Mas, quando o desejo fala mais alto do que as palavras, a instabilidade traça o seu rumo ao revelar uma vida diária de desfragmentação pessoal. O papel da mulher como indivíduo unicamente emocional é discutido pela própria personagem, que considera ser possível consumar o desejo sem envolver sentimentos e que, desta forma, revela uma mudança no paradigma dos papéis atribuídos a cada um dos géneros numa relação sexual.

BECKY I hate this whole thing like Women can't have sex without getting "emotionally involved". It's bullshit. I've had sex with loads of men and not given a shit afterwards.

OLIVER Nice.

BECKY No I mean it's such a delusion. "Oh you're so good Oliver I just can't help falling in love with you."

OLIVER I am good though.

BECKY Fuck off.

OLIVER Aren't I?

(Skinner, 2011: 86)

A necessidade física que Becky precisa de sentir preenchida é finalmente correspondida por Oliver, o homem que se torna seu amante depois de lhe vender uma bicicleta. A relação entre os dois mantém-se 
longe das emoções e - embora a ideia seja mais clara para Oliver do que para Becky - o reconhecimento do seu fim, sem qualquer compromisso, dita as regras de um jogo que promete castigar o jogador mais fraco. Curiosamente, o retrato que Skinner desenha da sua personagem feminina está muito próximo de uma certa moralização do desejo e das suas consequentes acções, e esta perspetiva só reforça a opinião de Aleks Sierz (2011) acerca do facto de que as peças dos anos 2000 representam muito frequentemente as mulheres como sozinhas e desesperadas.

Em Scarborough (2008), peça escrita por Fiona Evans, o desejo sexual assume a forma da tão representada sequência narrativa onde professor(a) se transforma em adulto atraído (será que em algum momento se poderá dizer apaixonado?) por um(a) aluno/a. Nesta tentativa de dar uma nova roupagem a esta temática, Evans divide a peça em duas partes, invertendo o género das personagens (professora-aluno/professor-aluna) para que o leitor possa explorar as duas visões e, de certa forma, perceber qual a que lhe incomoda mais e qual a que a sociedade mais condena. Na primeira parte, uma professora vai passar o fim de semana a um hotel, longe do sítio onde vive, com o aluno de quinze anos com quem mantém um caso. À medida que os observamos, na sua diferença de idades e mentalidades, e que escutamos o seu diálogo, conseguimos perceber a forma como a relação se vai desintegrando. O mesmo tipo de dispositivo dramático é utilizado na segunda parte, quando a dramaturga inverte o género das personagens. Scarborough apresenta claramente a imprudência como projeção do desejo sexual, independentemente do facto de esta surgir da parte dos adultos que têm consciência das consequências, ou do lado dos adolescentes, que aqui são apontados como os sedutores. A lei da sedução, tal como Baudrillard (1990) explica, assume a forma de um ritual ininterrupto onde sedutor e seduzido sobem constantemente a fasquia, num jogo que nunca termina já que é impossível determinar a linha que separa o vencedor do vencido. Mas, quando esse jogo se destina a aumentar os patamares do desejo e conduzir à consumação sexual, então, o sedutor e seduzido, recém-descidos da escalada orgástica, são confrontados com a realidade.

Enquanto obras artísticas, a literatura dramática e os espetáculos teatrais são capazes de criar, materializar e alimentar fantasias, gerando problemáticas que, por vezes, procuram captar a essência naturalista da realidade e que, entre outros aspetos, professam julgamentos morais provocando a capacidade interventiva - no domínio epistémico - do leitor e do espectador. A compreensão do mundo da peça é baseada, não 
obviamente de um modo exclusivo, nas experiências pessoais de cada um e na fórmula pela qual a sociedade (hetero)normativa se rege. Ao assumir este ponto de vista, questiona-se a natureza intrínseca do desejo nas suas diversas formas na arte e, mais especificamente, nas artes performativas. Alyce Mahon defende que o

desejo erótico é uma parte fundamental das nossas vidas privadas e públicas. [...] A arte erótica faz com que encaremos frontalmente o amor e o desejo sexual, a excitação e a atração carnal, assim como os desejos dos outros que talvez consideremos repulsivos. Também testa a nossa ideia individual e coletiva não só do que é «agradável» mas igualmente do que é «correto». (2007: intro)

Contextualizando as palavras de Mahon na dramaturgia contemporânea britânica, encontramos um exemplo no relacionamento estabelecido entre as personagens de Spur of the Moment (2010), de Anya Reiss: Delilah, uma jovem rapariga de doze (quase treze) anos e Danny, o inquilino de vinte e um anos que vive com ela e com os pais. Delilah parece querer crescer o mais depressa possível, idealizando uma ligação romântica com Daniel. Mas Delilah não finge ser só mais velha do que realmente é; na verdade, ela tenta encaixar o seu corpo de quase treze anos na pele de uma mulher que ainda não é, somente para o conquistar. Esta exposição, este testar de fronteiras estão carregados de uma forte energia sexual que, de alguma forma, escapa à supervisão dos pais porque estes estão completamente submersos no barulho ensurdecedor da sua própria relação. Reiss, que também ela própria tinha apenas catorze anos quando escreveu a peça, testa os limites quando posiciona o seu leitor perante uma dualidade: escolher a moralidade, a aplicação da lei e a consciência, ou, simplesmente, deixar transbordar a ideia romântica da paixão, esquecendo que Delilah ainda é uma criança e Daniel já é um adulto. É curioso constatar que, tanto em Spur of the Moment como em Scarborough, são as personagens mais novas, em ambos os casos menores, que são apontadas como peça fundamental para a ativação do desejo e da componente sexual. Nas palavras de Bataille (1980:114), «o romper inicial da vida sexual é mais frequentemente a procura da mulher pelo homem. Como são os homens que têm a iniciativa, as mulheres têm o poder de provocar o desejo dos homens». Mas será que os homens continuam a ter a exclusividade na iniciativa? Ou será que, embora esta geração de dramaturgos do novo milénio, claramente mais conservadora do 
que a anterior, está a escrever a representação de um modelo alternativo onde idade e género deixam de ser alvo de análise?

Outro exemplo de como se observa o erotismo e o desejo sexual de perspetivas ditas «aceitáveis» ou «acusatórias» pode ser lido em The Sugar Syndrome, peça escrita por Lucy Prebble, em 2003. Este texto representa o desejo sexual como uma força proibida, julgada e condenada pelas normas sociais e pelas leis judiciais. Na peça, Dani, uma rapariga de dezassete anos com distúrbios alimentares que vive numa casa destroçada pelos problemas familiares, conversa através da internet com Tim, um homem de trinta e oito anos, condenado, no passado, por molestar rapazes. Esta ligação, exatamente como na peça de Reiss, cresce sem que haja qualquer tipo de conhecimento ou supervisão por parte dos adultos. No entanto, quando Tim finalmente conhece Dani e se apercebe que é uma ela e não um ele, o desejo que tinha alimentado a ligação fica estilhaçado. Na opinião de Sierz (2011: 179), Prebble nunca julga as suas personagens, ela simplesmente identifica as «atrações de um comportamento perverso - e as suas consequências emocionais». A moralidade e a crítica são relegadas para o público que ainda está para definir as fronteiras do desejo e a repercussão da sua materialização.

Em 1955, Herbert Marcuse escreveu Eros and Civilization, marco histórico da emancipação da sexualidade. Neste ensaio, o filósofo alemão formulou uma crítica que expunha a sociedade de consumo como culpada por deliberadamente controlar e manipular as vontades e desejos do indivíduo. Embora tenha sido escrito há mais de cinquenta anos, é curioso constatar a pertinência das suas palavras e a forma como ainda ecoam na sociedade contemporânea. Todos os dias o sempre atento Big Brother, a glamorosa vida do Insta(gram) e a sociedade da fama e da fortuna, com todas as suas mil aplicações para namorar ou ter sexo, vendem a ideia do tipo de pessoa que cada indivíduo deve ambicionar ser para ser desejado, ou a própria ideia do tipo de pessoa com quem supostamente se deve fazer par. Os comportamentos que caracterizam esta sociedade são baseados precisamente na submissão do indivíduo a estas novas tendências. Consequentemente, mesmo quando se interpreta uma peça como mera representação naturalista da sociedade e das suas especificidades, é inegável o peso que a influência deste ambiente tem na mente dos dramaturgos e no resultado final da sua escrita. Tendo em conta este ponto de vista, a geração de dramaturgos do novo milénio tem vindo a revelar, nos seus textos, a preocupação com a construção de uma ligação alternativa com as suas vidas e as suas experiências pessoais, 
ignorando, de certa forma, o legado da geração anterior. Quando o amor é o tema em análise, estes autores parecem estar mais interessados na sua perseverança triunfante que na sua ligação com a sedução, o desejo e o sexo.

Numa outra perspetiva, e retratando uma geração mais nova, Nick Payne explora em Wanderlust (2010) as convicções de quem ainda está apenas a principiar o seu conhecimento acerca dos limites do corpo e das fronteiras que o outro representa. Na peça, Tim pede a Michelle que o ajude a iniciar a exploração da sua sexualidade. As personagens, ambas com quinze anos, mantêm uma relação de amizade, e o pedido cria alguma estranheza entre eles. Tim apressa-se a explicar que quer conquistar uma rapariga mais velha, que imagina inclusive que deve ter mais experiência do que ele, e Michelle aceita a proposta. É curioso como Payne nos insere no meio de uma súbita e momentânea relação adolescente, e nos faz sentir como uma espécie de voyeurs que não conseguem desviar o olhar apenas e porque reconhecem todos aqueles sinais. A interação entre estas duas pessoas, carregada de uma tensão sexual impulsionada pelas hormonas da adolescência, tem momentos que, num primeiro instante, provocam riso, mas que, ao serem aprofundados, criam um estado de inquietação. Esse desconforto é causado pelo conhecimento da realidade e pelo que, por exemplo, a pornografia ${ }^{7}$ pode despoletar na forma como a sexualidade é encarada num relacionamento, seja ele amoroso ou sexual.

Tim attempts to stimulate Michelle's clitoris.

How's that?

MICHELLE Um.

TIM It's sort of pretty hairy.

MICHELLE Thanks for that.

TIM I mean it's.

It's sort of pretty difficult getting back to the same spot each time. MICHELLE She's most likely gonna have pubic hair, Tim.

7 A pornografia feminista tem lutado ativamente contra a pornografia machista, alertando audiências e pais para a necessidade de uma educação sexual mais forte. A pornógrafa feminista Erika Lust tem sido uma das realizadoras mais ativas na veiculação desta mensagem, não só através dos seus filmes e, por vezes, da sua exibição pública, mas também através de conferências e da criação de um site para pais (http://thepornconversation.org). Para a edição de 2018 do Salon Erótico de Barcelona, foi difundido «Sin Éducacion Sexual», um vídeo realizado por Carles Valdés e apresentado pela atriz porno Sílvia Rubi, que serviu não só como campanha para o evento, mas também como defensor da importância da educação sexual (https://www.youtube.com/watch?v=PjOUh2Pe6JU). 
TIM As much as this though?

MICHELLE And goodbye.

Michelle moves.

TIM Sorry. Michelle, I. I'm sorry. That was. You know I mean I've never. I mean the only ones I've ever really seen are. Well, I mean they're bare.

MICHELLE Bare?

TIM Yeah, bare, like.

Sort of just makes it a lot easier to find y'way around.

MICHELLE Where on earth have you seen a bare vagina?

$\operatorname{TIM} \ldots$

MICHELLE You mean the internet?

(Payne, 2010: 39-40)

No novo milénio, a internet tem sido usada como ferramenta de livre acesso para a satisfação da curiosidade, do desejo, e até mesmo para a partilha de fantasias que possam ser consumadas na vida real. Esta nova realidade mudou a compreensão do desejo e da mecânica do sexo. A hiperestimulação do desejo sexual e do sexo conduz àquilo que Baudrillard (1990) apelida de perda do imaginário e, consequentemente, da sua realidade. No entanto, a sua expressão na dramaturgia representa uma vontade de expressar a temática através de uma abordagem mais realista. Se os dramaturgos conseguem ou não alcançar esse propósito, é uma história completamente diferente. Ao comparar esta geração com a do in-yer-face, é notória uma perspetiva mais conservadora no que diz respeito à sedução, ao desejo e mesmo ao sexo, como se o legado deixado por dramaturgos como Sarah Kane ou Mark Ravenhill não existisse. O trabalho realizado pelo Royal Court Theatre nos anos 90 conduziu a uma pequena fenda na exposição da intimidade da sociedade britânica e do impacto que esta representação teve na receção do público. Mas, com o acelerar da cultura, da sociedade e do culto do novo, a representação do desejo sexual na dramaturgia contemporânea britânica tem sido remetida para um lugar morno, onde um certo puritanismo substitui o choque e a brutalidade do passado. 


\section{REFERÊNCIAS BIBLIOGRÁFICAS}

BAtAille, Georges (1980), O erotismo, Lisboa, Antígona.

BAUd Rillard, Jean (1990), Seduction, Montréal, New World Perspective.

EVANS, Fiona (2008), Scarborough, Londres, Nick Hern Books.

HICKSON, Ella (2009), Eight, Londres, Nick Hern Books.

MAHON, Alyce (2007), Eroticism $\mho \widetilde{\sigma}$ Art, Oxford, Oxford University Press.

PAYNE, Nick (2010), Wanderlust, Londres, Faber \& Faber.

PREBBLE, Lucy (2007), The Sugar Syndrome, Londres, Bloomsbury.

REISs, Anya (2010), Spur of the Moment, Londres, Oberon Books.

SIE RZ, Aleks (2011), Rewriting the Nation: British Theatre Today, Londres, Methuen Drama.

SKINNER, Penelope (2011), The Village Bike, Londres, Faber \& Faber.

\section{CÁTIA FAÍSCO}

Frequenta o doutoramento em Estudos de Teatro na Faculdade de Letras da Universidade de Lisboa, onde desenvolve investigação acerca do desejo sexual na dramaturgia contemporânea britânica, sob a orientação de Rui Pina Coelho. A sua área de pesquisa contempla ainda o período do in-yer-face, e mais concretamente, do trabalho de Sarah Kane. É bolseira da Fundação para a Ciência e Tecnologia e, desde 2013, assistente convidada na área de Escrita Dramática e Dramaturgia, na Universidade do Minho. Foi assistente da direcção da licenciatura em Teatro, na mesma instituição. É cronista da revista $R \cup A$, onde escreve acerca da civilização do espectáculo. Integra o colectivo CASA como dramaturga. 